\title{
Five-Phase Permanent Magnetic Synchronous Motor Fed by Fault Tolerant Five Phase Voltage Source Inverter
}

\author{
Hichem Kesraoui $^{1}$, Hamdi Echeikh ${ }^{1}$, Atif Iqbal ${ }^{2}$, Med Faouzi Mimouni ${ }^{1}$ \\ ${ }^{1}$ National Engineering School of Monastir Tunisia \\ ${ }^{2}$ Electrical Engineering Department, Qatar University, Doha Qatar
}

\begin{tabular}{l}
\hline Article Info \\
\hline Article history: \\
Received Apr 15, 2016 \\
Revised Jun 29, 2016 \\
Accepted Jul 15, 2016 \\
\hline
\end{tabular}

Keyword:

Five-Phase Permanent

Magnetic Motor

Fuzzy Logic

Vector Controller

Voltage Source Inverter

\begin{abstract}
Multiphase machines have gained attention in numerous fields of pplications such as Aircraft, ship propulsion, petrochemical and automobiles, where high reliability is required. The additional number of phases guarantees that the system continues to operate in faulty conditions compared to the traditional three-phase machine due to the high degree of freedom. Among faults able to affect multiphase system, break between a machine phase and the voltage source inverter (VSI) degrade the performance of the control. In this paper, a five-phase permanent magnet synchronous machine (PMSM) is fed through a fault tolerant voltage source inverter with new structure to ensure drive continuity when open circuit occurs. The five phase PMSM is controlled with fuzzy logic regulator to minimize disturbance impact that can arise fault condition. Paper is accomplished with real time simulations using MATLAB-Simulink in order to validate the new topology and show the effectiveness of the proposed solution.
\end{abstract}

Copyright (C) 2016 Institute of Advanced Engineering and Science. All rights reserved.

\section{Corresponding Author:}

Kesraoui Hichem,

Electrical Engineering Department,

National Engineering School of Monastir Tunisia,

Ibn Eljazzar Street, 5000, Monastir, Tunisia.

Email: kesraouihichem@gmail.com

\section{INTRODUCTION}

Certain applications like electric vehicles, wind or marine current turbines and ships propulsion, require a high reliability of on-board equipment. The electrical machine is the heart of these applications and it is sometimes highly desirable even essential to keep its operation even under severe conditions where a failure emerges and the intervention becomes risky or too expensive.

A certain number of these applications then betted on the training system by supporting the multiphase machine where number of phases is higher than three, it offers a certain number of additional freedom degrees compared to the classical three-phase machines [1]. These freedom degrees can be exploited to improve the torque density [2] or to control several machines serial or parallel connected [3] or to maintain a certain operation during the fault conditions.

A defect on an inverter's or in its connection with the corresponding multiphase machine winding generally leads to degradation by rupture of a stator phase. It is the most common fault in machine-converter association [4], this causes the annulation of the current in the corresponding phase and thus the appearance of a torque ripple. The development of control which maintains a constant torque is more than necessary. In the literature many research works addressed to fault conditions such as in [5] a predictive control scheme is modified to allow post fault operation of a five-phase drive when one phase is open. In [6], new currents are imposed to minimize joule's losses in remaining phases and avoid torque ripple when one phase goes in open-circuit, when the control scheme is validated by simulating an actuation system with a five-phase segment motor. 
In [7], optimal currents which minimise joule's losses are obtained by applying instantaneous power balance theory after introducing the concept of fault tolerant currents in the spatially symmetrical phases. The goal of all these works is to compensate fault described by an open phase and keep operating drive system with the remaining healthy phases, no additional hardware was proposed, nonetheless, it may be more beneficial and less expensive. Several open circuit faults can damage the performance system [8]; they include the open phase machine. Phase can be lost in the machine side (stator winding part), one need to consider the remaining phases only for the control purpose. It can also be lost in the inverter side, therefore, leg become unable to ensure supply.

Focusing on the energy conversion chain, the faulty mode appears as soon as a component of the supply of the multiphase machine is defected. Among its origins, one note: faults related to ON/OFF switches and faults related to connection machine-inverter.

When the fault on an element directly implies opening phase, this leads to annulation of the corresponding current. On the other hand, if a controlled switch does not open or if a machine winding is short-circuited an overcurrent appears, the fuse protection in series with the transistor intervenes and eliminates the current increase to protect the machine and avoid conductors overheating. Hence, in the two previous fault-cases current is zero. The immediate consequence is unbalanced in the magnetic mortice force (MMF), which involves creating torque harmonics, then adverse effects on the driven mechanism appears. Moreover, the opening of one phase does not make it possible any more the inverter to feed corresponding winding. A stator potential of the machine is not controlled any more. This aspect particularly takes into account synchronous permanent magnet machines, because flux produced by remaining phases generates uncontrolled voltage in the lost phase.

The present work focus on fault tolerant control of five-phase PMSM by reconfiguration of its inverter after one open leg connection, seeking prevention of further damages. The proposed strategy has no impact on control technique used in healthy condition.

As far as the authors know that there is no work extended on the multiphase motor and its association with multiphase VSI. The paper is structured as follow: Section 2 presents modelling of fivephase permanent motor and its inverter, section 3 introduced the proposed solution after an open connection, section 4 describes fuzzy logic controller used to regulate speed motor followed by simulation results and discussion. Conclusion will be object of section 5 .

\section{FIVE-PHASE SYSTEM MODELING}

The five-phase PMSM behaviour obeys a certain number of equations expressed all in a natural base. These equations present a strong coupling which can obstruct the development of its control. With the five-order transformation (1) of Concordia, one manages to overcome this problem by obtaining the system of decoupled equations (2).

Finally, by applying Park transformation (3), one obtains the system (4) considered as a suitable model of control where mechanical equation is added.

$$
C=\sqrt{\frac{2}{5}}\left[\begin{array}{ccccc}
1 & \cos \left(\frac{2 \pi}{5}\right) & \cos \left(\frac{4 \pi}{5}\right) & \cos \left(\frac{6 \pi}{5}\right) & \cos \left(\frac{8 \pi}{5}\right) \\
0 & \sin \left(\frac{2 \pi}{5}\right) & \sin \left(\frac{4 \pi}{5}\right) & \sin \left(\frac{6 \pi}{5}\right) & \sin \left(\frac{8 \pi}{5}\right) \\
1 & \cos \left(\frac{4 \pi}{5}\right) & \cos \left(\frac{8 \pi}{5}\right) & \cos \left(\frac{12 \pi}{5}\right) & \cos \left(\frac{16 \pi}{5}\right) \\
0 & \sin \left(\frac{4 \pi}{5}\right) & \sin \left(\frac{8 \pi}{5}\right) & \sin \left(\frac{12 \pi}{5}\right) & \sin \left(\frac{16 \pi}{5}\right) \\
\frac{1}{\sqrt{2}} & \frac{1}{\sqrt{2}} & \frac{1}{\sqrt{2}} & \frac{1}{\sqrt{2}} & \frac{1}{\sqrt{2}}
\end{array}\right]
$$

$$
\left\{\begin{array}{l}
v_{S \alpha 1 \beta 1}=R \cdot i_{s \alpha 1 \beta 1}+L_{p} \cdot \frac{d i_{s \alpha 1 \beta 1}}{d t}+\frac{d \lambda_{r \alpha 1 \beta 1}}{d t}=R \cdot i_{s \alpha 1 \beta 1}+L_{p} \cdot \frac{d i_{s \alpha 1 \beta 1}}{d t}+E_{\alpha 1 \beta 1} \\
v_{S \alpha 2 \beta 2}=R \cdot i_{s \alpha 2 \beta 2}+L_{S} \cdot \frac{d i_{s \alpha 2 \beta 2}}{d t}+\frac{d \lambda_{r \alpha 2 \beta 2}}{d t}=R \cdot i_{s \alpha 2 \beta 2}+L_{s} \cdot \frac{d i_{s \alpha 2 \beta 2}}{d t}+E_{\alpha 2 \beta 2}
\end{array}\right.
$$




$$
\begin{aligned}
& P=\left[\begin{array}{cccc}
\cos \left(\theta_{e}\right) & \sin \left(\theta_{e}\right) & 0 & 0 \\
-\sin \left(\theta_{e}\right) & \cos \left(\theta_{e}\right) & 0 & 0 \\
0 & 0 & \cos \left(3 \theta_{e}\right) & -\sin \left(3 \theta_{e}\right) \\
0 & 0 & \sin \left(3 \theta_{e}\right) & \cos \left(3 \theta_{e}\right)
\end{array}\right] \\
& \left\{\begin{array}{l}
V_{d 1}=R \cdot I_{d 1}+L_{p} \cdot \frac{d I_{d 1}}{d t}-L_{p 1} \cdot \omega_{e} \cdot I_{q 1} \\
V_{q 1}=R \cdot I_{q 1}+L_{p} \cdot \frac{d I_{q 1}}{d t}+L_{p 1} \cdot \omega_{e} \cdot I_{d 1}+\omega_{e} \cdot \lambda_{r d 1} \\
V_{d 2}=R \cdot I_{d 2}+L_{S} \cdot \frac{d I_{d 2}}{d t}+3 \cdot L_{s} \cdot \omega_{e} \cdot I_{q 2} \\
V_{q 2}=R \cdot I_{q 2}+L_{S} \cdot \frac{d I_{q 2}}{d t}-3 \cdot L_{S} \cdot \omega_{e} \cdot I_{d 2} \\
J \cdot \frac{d \Omega}{d t}+f \cdot \Omega=T_{e m}-T_{r} \\
T_{e m}=p \cdot \lambda_{r d 1} \cdot I_{q 1}=p \cdot \sqrt{\frac{5}{2}} \cdot \lambda_{m} \cdot I_{q 1}
\end{array}\right.
\end{aligned}
$$

Where: ${ }_{e}={ }^{\mathrm{o}} \omega_{e} d t$ and ${ }^{\omega} e_{\text {design the electrical motor speed }} \omega_{e}=p \Omega$

Power circuit topology of a five-phase voltage source inverter (VSI) is a standard structure (figure1) containing ten switches $S_{i}$ and $S_{i}^{\prime}(i=1 \ldots 5)$ offering $2^{5}=32$ combinations, each switch consists of two semiconductor devices, connected in anti-parallel: a bipolar transistor or IGBT and a diode. Inverter's input is a DC voltage regarded further on being constant $V_{d c}$. The load is a why coupled five-phase permanent magnet synchronous machine (PMSM) of which phase voltages are denoted $v_{i n}(i=1 \ldots 5)$. The relation between these output voltages and inverter's switches are given in (5).

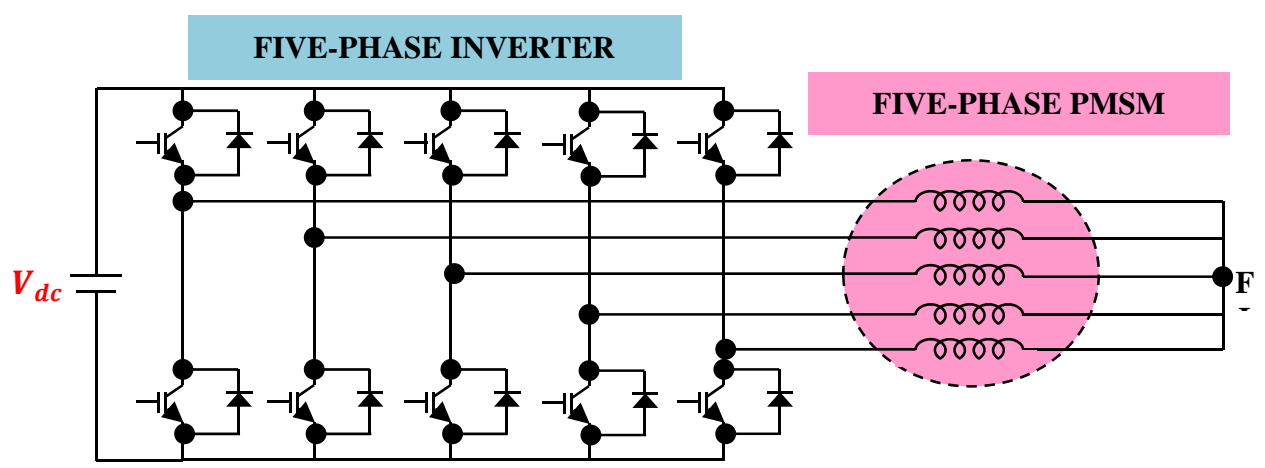

Figure 1. Five-phase voltage source inverter

$$
\left[\begin{array}{c}
v_{1 n} \\
v_{2 n} \\
v_{3 n} \\
v_{4 n} \\
v_{5 n}
\end{array}\right]=\frac{V_{d c}}{5}\left[\begin{array}{ccccc}
4 & -1 & -1 & -1 & -1 \\
-1 & 4 & -1 & -1 & -1 \\
-1 & -1 & 4 & -1 & -1 \\
-1 & -1 & -1 & 4 & -1 \\
-1 & -1 & -1 & -1 & 4
\end{array}\right] \cdot\left[\begin{array}{c}
S_{1} \\
S_{2} \\
S_{3} \\
S_{4} \\
S_{5}
\end{array}\right]
$$


Since it is about five-dimension and according to five phase PMSM modelling, vectors in two level VSI can be projected into two two-dimensional subspaces $\left(\alpha_{1} \beta_{1}\right)$ and $(\alpha 2 \beta 2)$ [9] as depicted in figure2. Space vectors form 3 decagons in each plan. In the literature, for three-phase inverter, control of switches can be ensured with different techniques of pulse width modulation (PWM) such as sinusoidal pulse width modulation (SPWM) and space vector pulse width modulation (SVPWM). There is an increasing trend of using SVPWM technique due to the easiness of digital realization, reducing harmonics and switching losses with better dc bus utilization [10]. With five-phase inverter, SVPWM is ensured after satisfying certain criteria [11]. Sector in which evolves the vector reference voltage is determined first in $\left(\alpha_{1} \beta_{1}\right)$ plan, then, according to its parity, a temporal average of four vectors limiting the studied sector ( 2 large and 2 medium vectors) adequately selected is calculated allowing to filter, in $\left(\alpha_{2} \beta_{2}\right)$ plan, third harmonic.
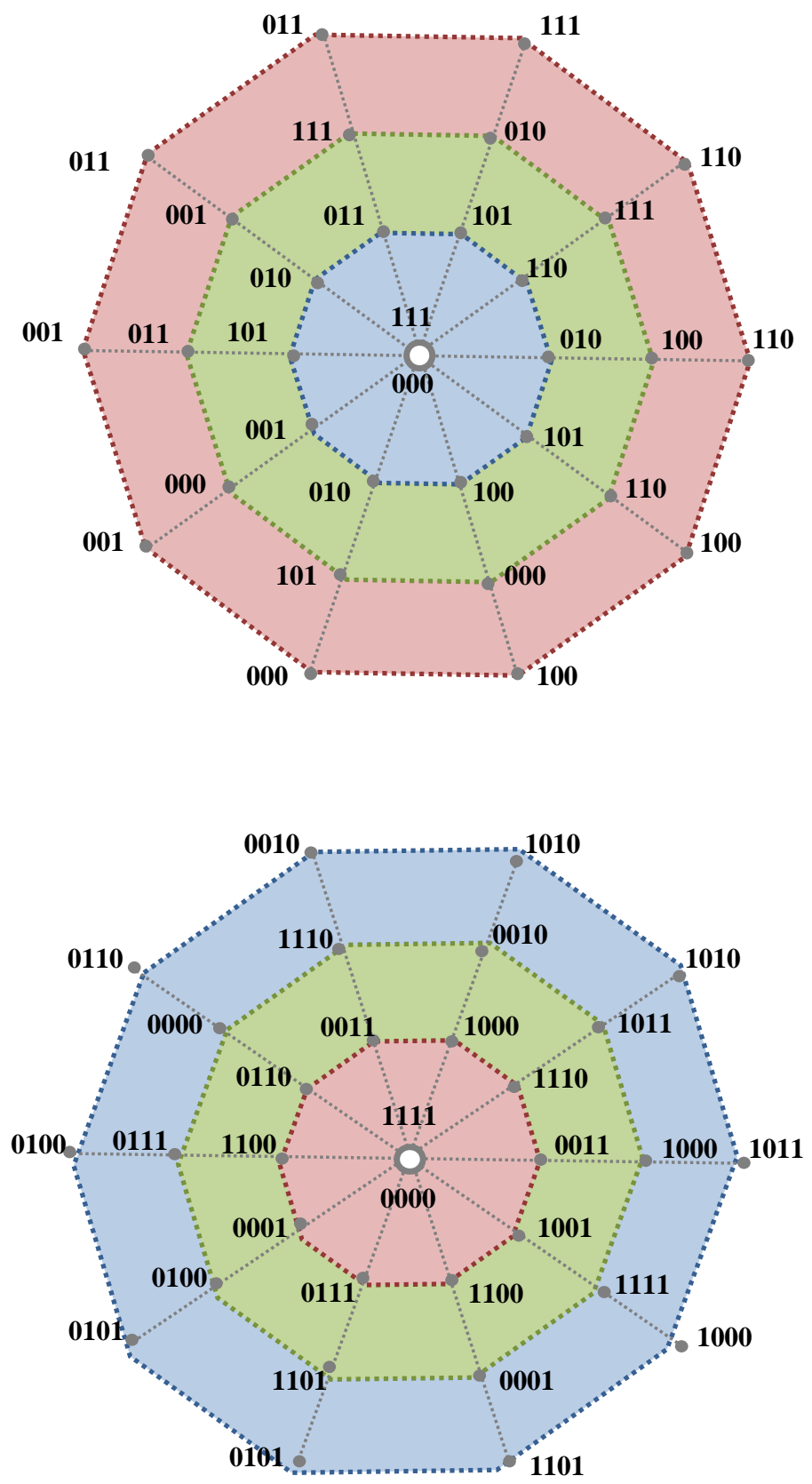

Figure 2. Switching vectors in reference frames $\left(\alpha_{1} \beta_{1}\right)$ and $\left(\alpha_{2} \beta_{2}\right)$ 
The sector in which the reference vector evolves at a given moment can be identified by respecting an algorithm where components of this vector are determined and compared [12], it can also be identified by calculating switching functions representing each one a half plan of membership of the reference [13] or simply by determination of the phase reference vector $\alpha$ such as :

$$
N_{\text {sect }}=\operatorname{int}\left(\frac{\alpha}{\frac{\pi}{5}}\right)
$$

Where the function int (.) provides the integer part of element between brackets.

Topology given in Figure 1 does not allow a fault tolerant control in open circuit fault condition: the bipolar transistor or the IGBT can fall in the OFF state and remains in this situation regardless of the gate voltage value. An open circuit fault occurs due to lifting of bonding wires caused by thermic cycling. It may be caused by a driver fault or a short circuit fault induced IGBT rupture.

Open circuit faults do not cause system shut-down but degrade its performance. The proposed solution consists of anticipation by envisaging a rupture between one phase machine and the corresponding inverter arm: an additional switch, initially opened, intervenes by its closing to connect lost phase machine to the mid-point $\mathrm{O}$ of DC bus (Figure 3).

Five new switches $k_{i}(i=1 \ldots 5)$, normally opened, are prepared to commutate, any inverter arm can be disconnected, the corresponding switch have to balance and save the disconnected phase.

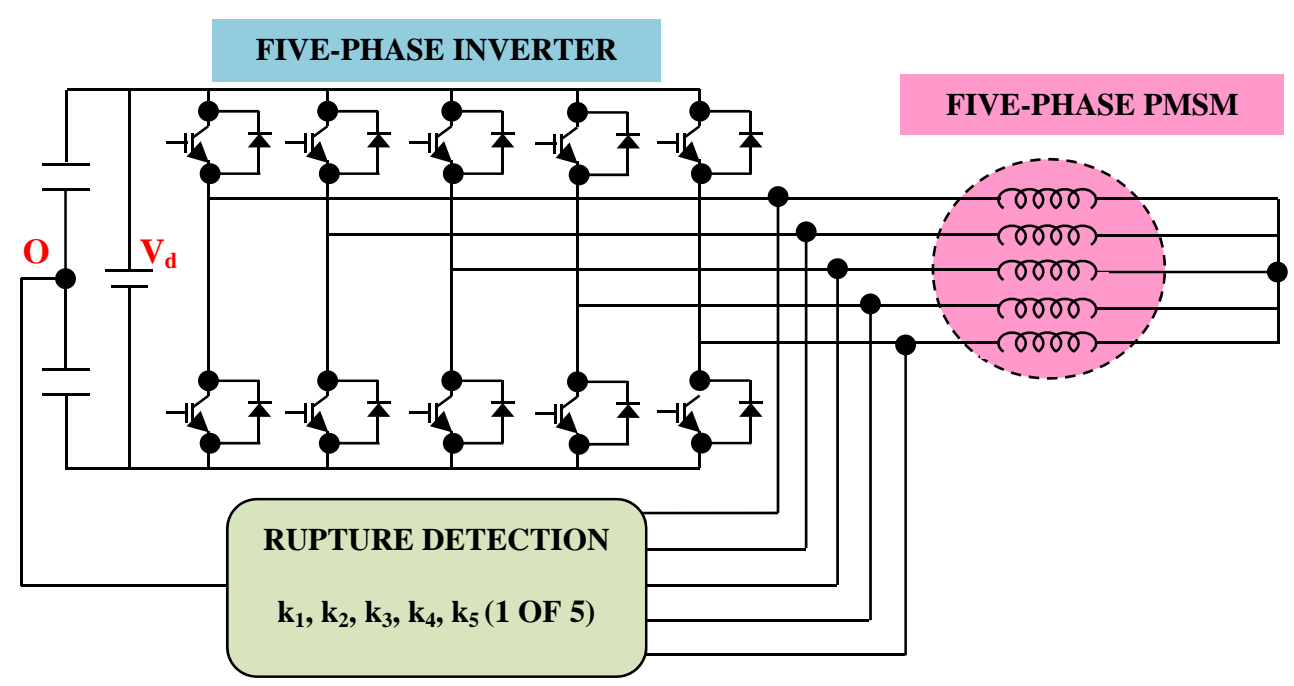

Figure 3. Tolerant arm-phase rupture configuration

\section{ASSOCIATION BEHAVIOR AFTER LEG-PHASE BREAK}

Since this study concern the loss of only one phase, suppose that at a given time, connection between phase 5 and VSI is lost, switch $k_{5}$ is ON, five-phase PMSM is then supplied through an inverter with new structure using four arms, only $2^{4}=16$ combinations are possible, relation (1) is no longer available, it's replaced in this case by equation (7) and 16 different vectors irregularly spaced with six different amplitude form an unbalanced polygon in each $\left(\alpha_{1} \beta_{1}\right)$ and $\left(\alpha_{2} \beta_{2}\right)$ plans, so, using SVPWM leads to treat different cases and may not be simple.

Aiming to adjust the output current and to track the current reference, hysteresis current control is used. Comparing the instantaneous current in the five-phase PMSM with the reference signal, the controller should adjust the duty cycle of the PWM signal in the inverter [14]. 


$$
\left[\begin{array}{c}
v_{1 n} \\
v_{2 n} \\
v_{3 n} \\
v_{4 n} \\
v_{5 n}
\end{array}\right]=\frac{V_{d c}}{5}\left[\begin{array}{rrrrr}
4 & -1 & -1 & -1 & -1 \\
-1 & 4 & -1 & -1 & -1 \\
-1 & -1 & 4 & -1 & -1 \\
-1 & -1 & -1 & 4 & -1 \\
-1 & -1 & -1 & -1 & -1
\end{array}\right]\left[\begin{array}{l}
S_{1} \\
S_{2} \\
S_{3} \\
S_{4} \\
S_{5}
\end{array}\right]-\frac{V_{d c}}{5}\left[\begin{array}{c}
0.5 \\
0.5 \\
0.5 \\
0.5 \\
-2
\end{array}\right]
$$

\section{POST FAULT OPERATION USING FUZZY LOGIC CONTROL}

To verify the studied new configuration, a five phase PMSM is fed through the VSI with fault tolerant structure. Since the five-phase PMSM is a nonlinear system, a fuzzy control is applied in the speed loop and provides $I q$ current reference.

The main idea consists on using control insensitive to disturbance and nonlinearities .The intelligent techniques based on fuzzy logic didn't stop showing their performances and their effectiveness and several works confirm it since work of Mamdani in 1974 [15].

Contrary to the classical regulators, the adoption of a fuzzy logic regulator in speed loop does not require a precise mathematical knowledge concentrated around the process, but it requires a base of several rules calling on linguistic variables. An expert feeds this base by preliminary data, by envisaged or desirable results.

Although the mathematical models of the electric machine are known and the conventional regulators are always present in most of the loops, their use becomes limited in front of sudden change of machine model, this change can be related to the parametric variations or accidental opening of one or more phases supply.

For this reason, one presents the contribution of fuzzy logic regulator to check the performance control. In fuzzy control systems, one can distinguish three principal parts [16]: the fuzzification where one define for each system input a speech universe and a partitioning of this universe in vague units, then a mechanism of inference calculates the fuzzy subset relating to the control of the system being based on linguistic rules initially defined by an expert. Finally the defuzzification which transform the fuzzy subset into a non-vague value allowing the effective control of the system. For the case of the five-phase PMSM, one define to the fuzzy regulator two input variables: the speed error « $e$ » and its variation « de » (Figure 4).

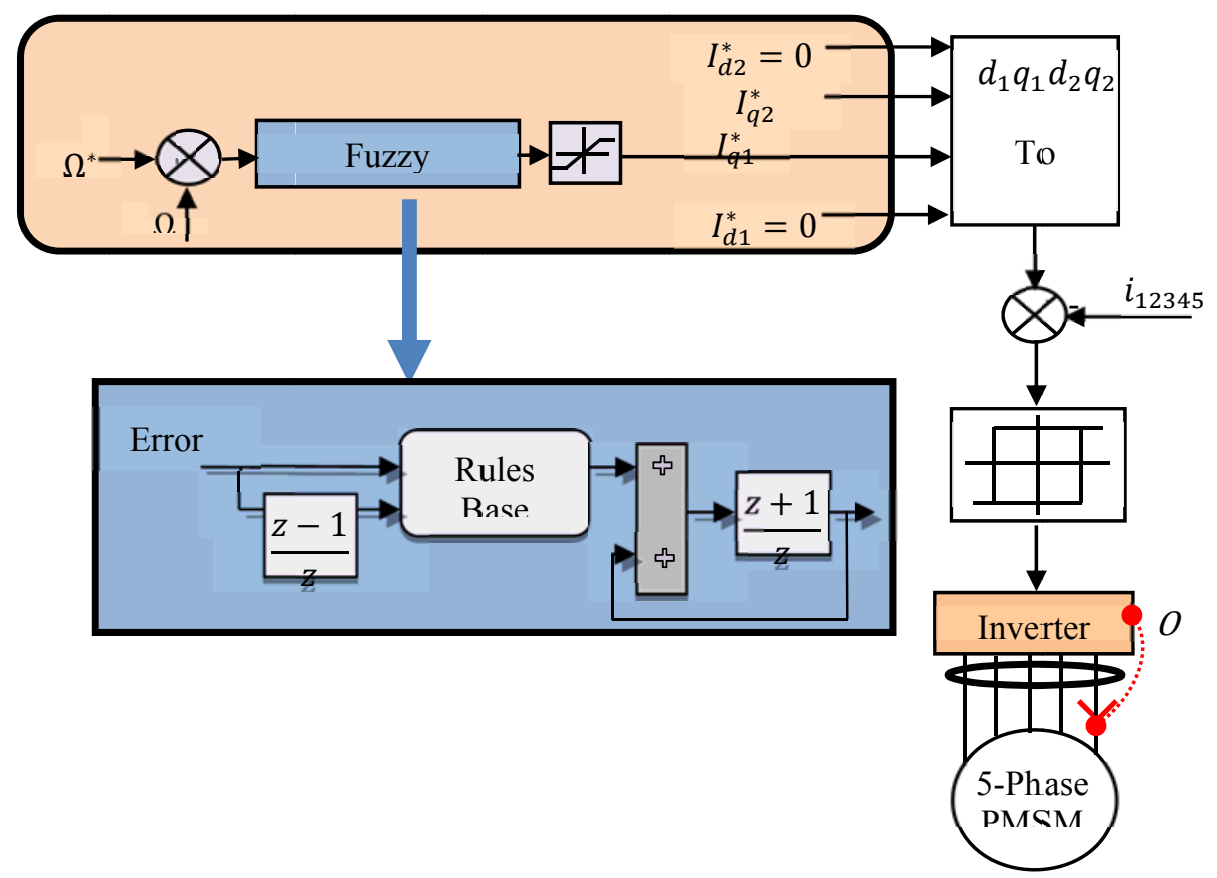

Figure 4. Control diagram 
A database of 49 rules can be summarized in table 1 where seven membership functions is defined for each input, they are noted respectively $N G, N M, N P, E Z, P P, P M$ and $P G$ to be able to describe, in a linguistic way, the state of the error and its variation. Membership functions are triangular form, the fuzzification method adopted is the max-min method and the defuzzifiation is centroid method.

Table 1. Definition of base rules for error and its variation

\begin{tabular}{llllllll}
\hline & $A$ NG & NM & NP & EZ & PP & PM & PG \\
\hline NG & NG & NG & NG & NM & NM & NP & EZ \\
NM & NG & NG & NG & NM & NP & EZ & PP \\
NP & NG & NG & NM & NP & EZ & PP & PM \\
EZ & NG & NM & NP & EZ & PP & PM1 & PG \\
PP & NM & NP & EZ & PP & PM & PG & PG \\
PM & NP & EZ & PP & PM & PG & PG & PG \\
PG & EZ & PP & PM & PG & PG & PG & PG \\
\hline
\end{tabular}

\section{RESULTS AND ANALYSIS}

Simulation results are illustrated in Figure 5 using fuzzy logic controller in healthy and faulty modes. The parameters of the studied five-phase PMSM and its inverter are specified in Table 2. The motor is drived at $1500 \mathrm{rpm}$ without load.

Figure 5.a presents the reference and actual speed, Figure 5.b shows electromagnetic torque, stator currents in the rotating frame $\left(d_{1} q_{1}\right)$ are given in Figure 5.c and given in Figure 5.d when expressed in the reference frame $\left(\alpha_{1} \beta_{1}\right)$. Figure 5.e and Figure 5.f highlight the revolutions of current and voltage in the reference frame respectively. Finally, disconnected phase current and its zoom are given in Figure 5.g and Figure 5.h.

Table 2. Parameters of five phase PMSM and inverter

\begin{tabular}{ccc}
\hline Variable & Value & Unit \\
\hline $\mathrm{R}$ & 0.67 & $\Omega$ \\
$\mathrm{L}_{\mathrm{p}}$ & 3.2 & $\mathrm{mH}$ \\
$\mathrm{L}_{\mathrm{s}}$ & 0.93 & $\mathrm{mH}$ \\
$\phi_{\mathrm{m}}$ & 0.2 & $\mathrm{~Wb}$ \\
$\mathrm{~J}$ & 0.001 & $\mathrm{Kg} \cdot \mathrm{m}^{2}$ \\
$\mathrm{~V}_{\mathrm{dc}}$ & 400 & $\mathrm{~V}$ \\
$\mathrm{~F}_{\mathrm{e}}$ & 5000 & $\mathrm{~Hz}$ \\
\hline
\end{tabular}

Five phase PMSM is running while a connection rupture between phase number 5 and the corresponding leg inverter happens at time fault $t_{f}=0.5 \mathrm{~s}$, at $t=0.55 \mathrm{~s}$, additional switch commutate to bring operating system back, phase number 5 is connected again, but to middle point $\mathrm{O}$ as it mentioned before.

One can notice the impact of this disturbance in all waveforms during lost phase time $\left(t_{f}=0.05 \mathrm{~s}\right)$. Indeed, motor speed reaches rapidly its final value with a small overshoot, rise and response times almost equal respectively to $7.7 \mathrm{~ms}$ and $8.5 \mathrm{~ms}$. This confirms the high dynamic and efficiency of fuzzy controller even at fault instant: impact of disturbance is almost insignificant.

The electromagnetic torque has some peaks at $t_{f}$ and an acceptable ripple ensured by the adopted solution and $I_{q l}$ current has the same torque's form which permit to verify last relation in (4) where torque is controlled with $I_{q l}$ current only, $I_{d l}$ is kept zero. 


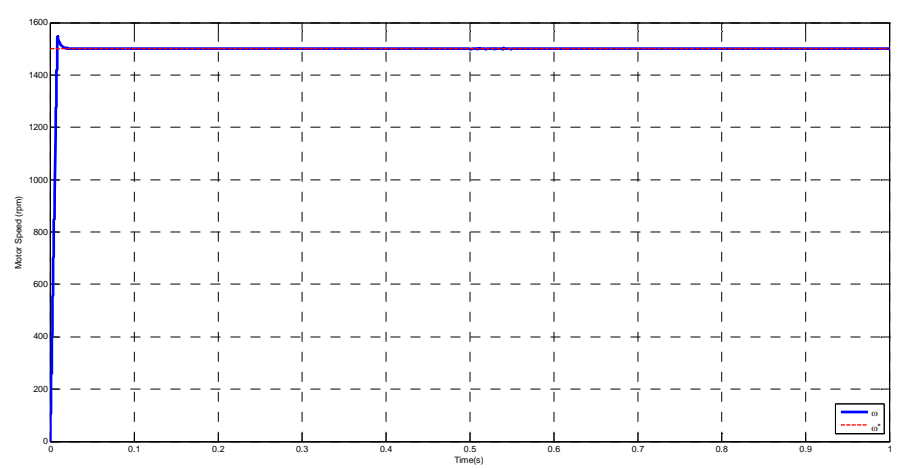

(a)

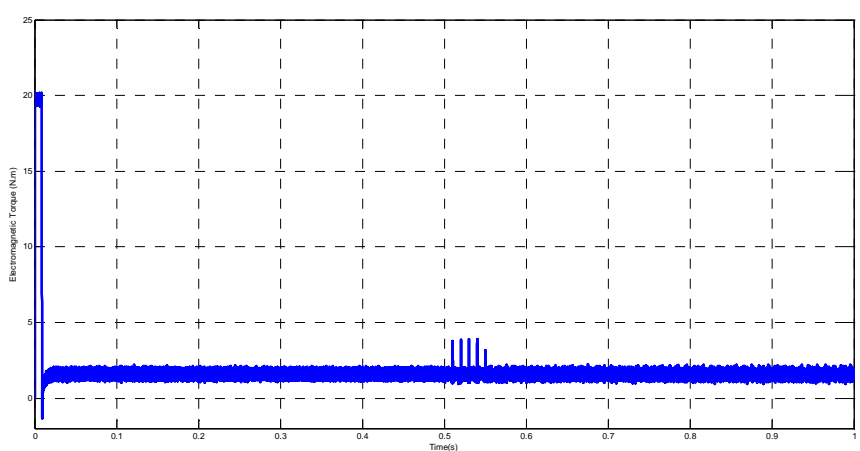

(b)

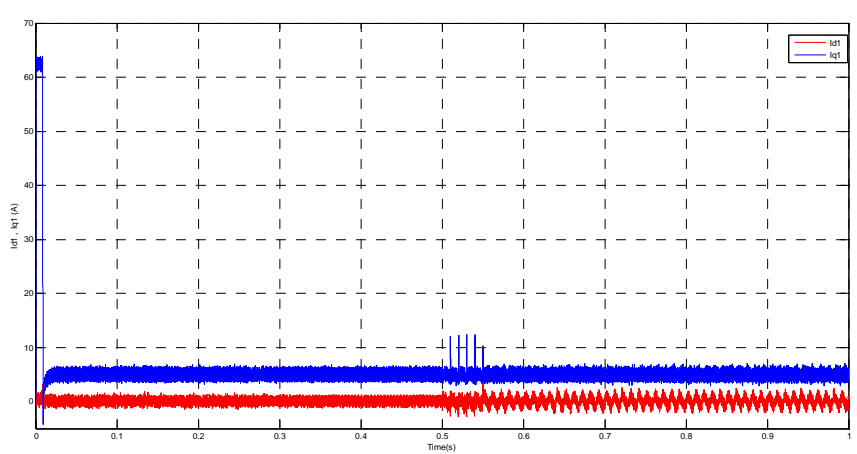

(c)

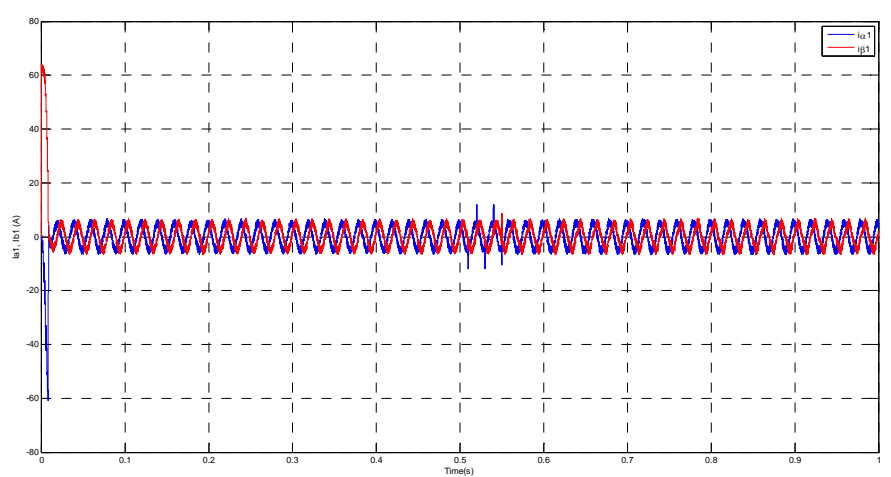

(d) 


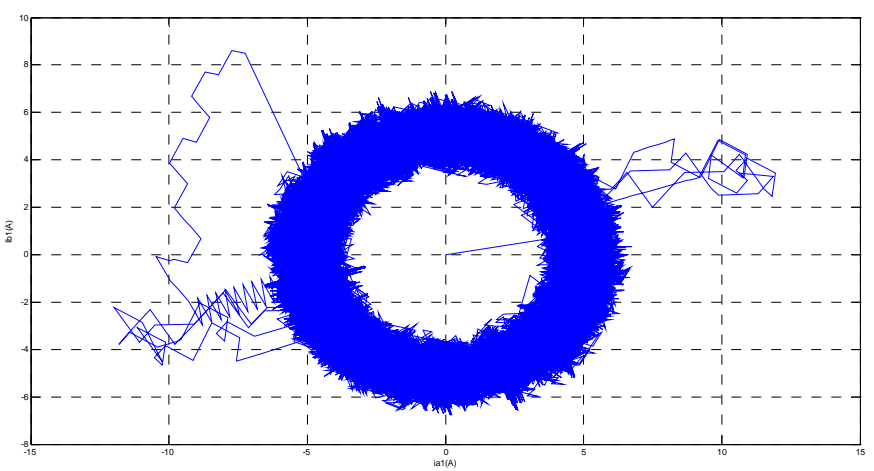

(e)

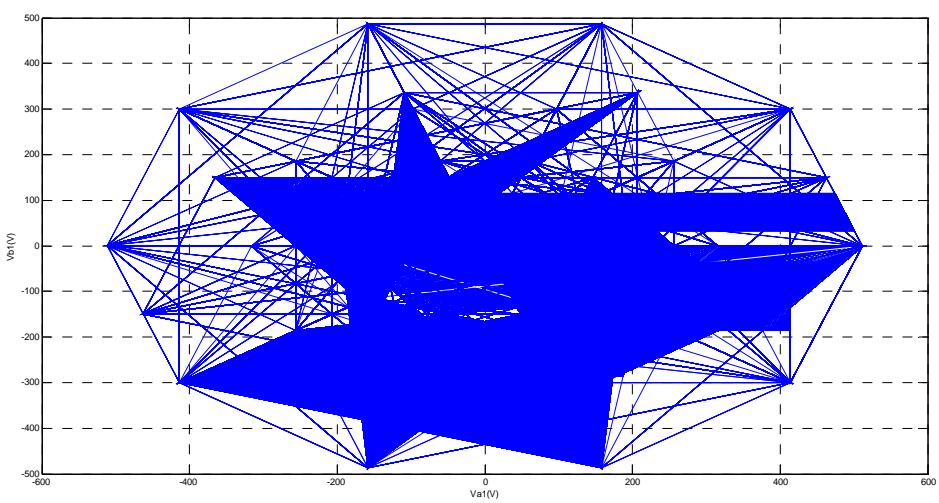

(f)

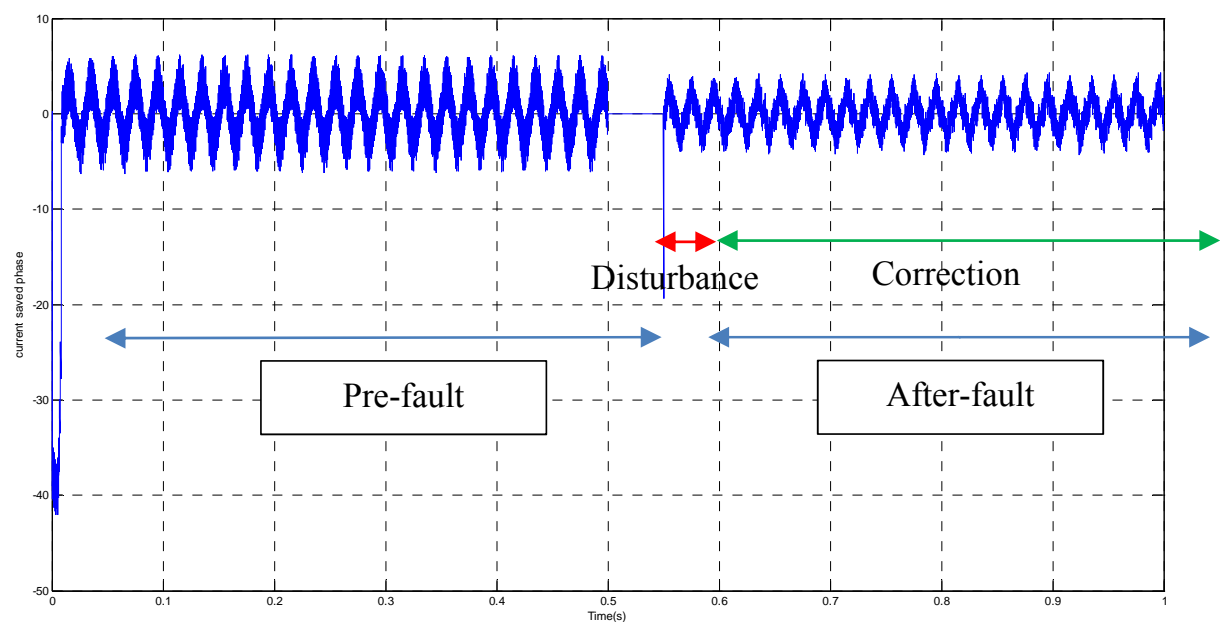

(g) 


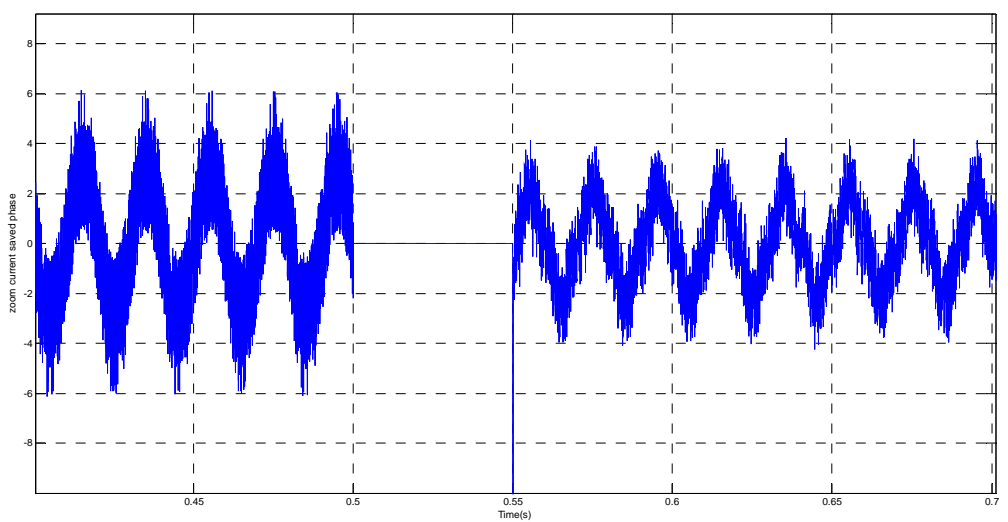

(h)

Figure 5. Simulation results using fuzzy logic controller in healthy and faulty modes

\section{CONCLUSION}

A wye coupled five-phase PMSM has been studied in a particular case when connection between one phase and leg inverter is severed. Caused disturbance has been extenuated by connecting the lost phase to mid-point DC bus inverter, forms of different responses have been improved by the use of fuzzy logic controller. One can notice that successful operation without changing or modifying the used controller neither the machine modelling is guaranteed, this minimize the tolerant solution cost and downtime which have a real impact on the whole system revenue.

\section{REFERENCES}

[1] L. Parsa, "On advantages of multi-phase machines," Industrial Electronics Society, 2005. IECON 2005. 31st Annual Conference of IEEE, pp. 6, 2005.

[2] P. Zhao and G. Yang, "Torque Density Improvement of Five-Phase PMSM Drive for Electric Vehicles Applications."

[3] E. Levi, "Supplying Two Five-Phase Series-Connected Machines," pp. 222-227, 2006.

[4] J. Fu and T. A. Lipo, "Disturbance-Free Operation of a Multiphase Current-Regulated Motor Drive with an Opened Phase," vol/issue: 30(5), pp. 5-12, 1994.

[5] H. Guzmán, et al., "Fault - Tolerant Current Predictive Control of Five - Phase Induction Motor Drives with an Open Phase," pp. 3680-3685, 2011.

[6] F. Baudart, et al., "Control strategy with minimal controller reconfiguration of fault tolerant polyphase PMSM drives under open circuit fault of one phase," Electrical Machines (ICEM), 2010 XIX International Conference on., pp. 1-6, 2010.

[7] S. Dwari, et al., "Optimal Current Waveforms for Five-phase Permanent Magnet Motor Drives under Open- circuit Fault," pp. 1-5, 2008.

[8] B. J. Rabi, "Fault Tolerant Control in ZSource Inverter Fed Induction Motor," Int. J. Power Electron. Drive Syst., vol/issue: 1(1), pp. 29-35, 2011.

[9] W. N. W. A. Munim, et al., "Switching technique comparison for multi-phase inverters," Power Engineering and Optimization Conference (PEOCO), 2013 IEEE 7th International. pp. 155-160, 2013.

[10] A. Porwal, "Modeling and Simulation of SVPWM Based Application," Int. J. Appl. Power Eng., vol/issue: 3(2), 2014.

[11] A. Iqbal, et al., "Space Vector Modulation Schemes for a Five-Phase Voltage Source Inverter Keywords Modelling of a Five-Phase VSI," pp. 1-12, 2005.

[12] T. T. Liu, et al., "Simulation of PMSM Vector Control System Based on Matlab/Simulink," Measuring Technology and Mechatronics Automation, 2009. ICMTMA '09. International Conference on, vol. 2, pp. 343-346, 2009.

[13] A. Lega, et al., "General Theory of Space Vector Modulation for Five-Phase Inverters," pp. 237-244, 2008.

[14] P. Qian and Y. Zhang, "Electronics and Signal Processing: Selected Papers from the 2011 International Conference on Electric and Electronics (EEIC 2011) in Nanchang, China on June 20--22, 2011, Volume 1," W. Hu, Ed. Berlin, Heidelberg, Springer Berlin Heidelberg, pp. 889-895, 2011.

[15] E. H. Mamdani, “Application of Fuzzy Logic to Approximate Reasoning Using Linguistic Synthesis,” vol/issue: C(12), pp. 1182-1191, 1977

[16] Z. Salem, "DSP Based Vector Control of FivePhase Induction Using Fuzzy Logic Control," Int. J. Power Electron. Drive Syst., vol/issue: 2(2), pp. 192-202, 2012. 


\section{BIOGRAPHIES OF AUTHORS}

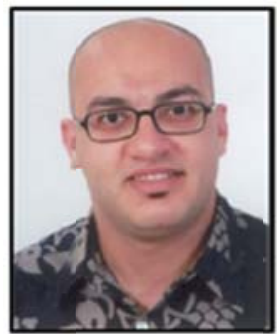

Hichem Kesraoui, was born in Mahdia, Tunisia in 1979. He received his Electrical Engineer Diploma and Master Degree in 2002 and 2009 from ENIM, Monastir, Tunisia. He is currently Master Technologist Professor of Higher Institute of Technological Studies of Mahdia (ISET Mahdia). His research interests are Electrical Machines Drives, Multiphase Machine Drives, Power Electronics and Nonlinear Control Systems related to renewable energy.

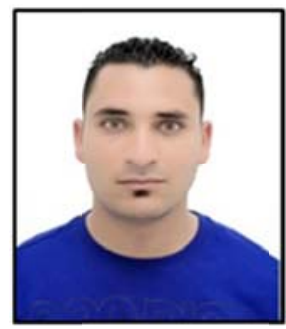

Hamdi Echeikh, was born in Tozeur, Tunisia in 1988. He received his Electrical Engineer diploma and Master Degree from ENIM, Monastir, Tunisia in 2011 and 2013, respectively. Currently he is PhD student at National Engineering School of Monastir. His research interests are Multiphase Machine Drives, Renewable Energies, Power Electronics, Linear and Nonlinear Control Systems and Design of observers applied for Electrical machines.

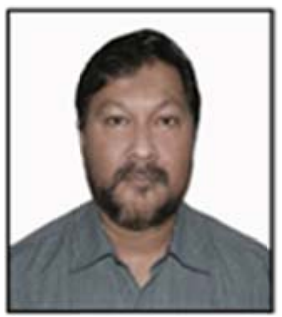

Atif Iqbal, (S'04-M'09) received the B.Sc. and M.Sc.Engineering (Electrical) degrees from Aligarh Muslim University (AMU), Aligarh, India, in 1991 and 1996, respectively, and the Ph.D. degree from Liverpool John Moores University (LJMU), Liverpool, U.K., in 2006. From 1991, he was with the Department of Electrical Engineering, AMU, where he was a Lecturer and a Reader. He is currently with the Electrical and Computer Engineering Program at Texas A\&M Universityat Qatar, Doha, Qatar. His current research interests include power electronics and multiphase motor drives. Dr. Iqbal is a recipient of the Maulana Tufail Ahmad Gold Medal for standing first in B.Sc. Eng. exams in 1991, and the AMU and the Engineering and Physical Sciences Research Council (EPSRC), Govt. of U.K. Fellowship for pursuing the Ph.D. degree at LJMU.

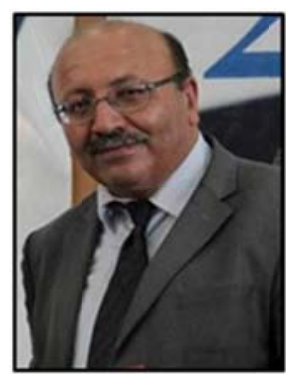

Mohamed Faouzi Mimouni, received his Mastery of Science and DEA from ENSET, Tunis, Tunisia in 1984 and 1986, respectively. In 1997 he obtained his Docttorate Degree in Electrical Engineering from ENSET, Tunis. He is currently Professor of Electrical Engineering at National School of Engineers, Monastir, Tunisia. His specific research interests are in the area Power Electronics, Motor Drives, Solar and Wind Power generation. 